62 are on fractions of the same hand sample, which differ widely in their mineral compositions. If the alteration was such as to cause significant deviation from the true age, it must further be postulated that the alteration affected the concentrations of rubidium and strontium in the different minerals in the same proportions. This is thought to be unlikely. Secondly, the alterations at levels 61 and 62 are markedly different in degree, and it would be unlikely that the balance of rubidium and strontium would remain the same in both. If the alteration took place in the immediately post-intrusion period, 'true' and 'measured' ages would be coincident for both samples.

The age reported here differs widely from that inferred by Cooke ${ }^{2}$, but does not involve any change in the relationship of the dykes with surrounding formations. Cooke's estimate was based on the relation of the Waterberg to the Bushveld igneous complex, which was thought to be late pre-Cambrian. The Bushveld igneous complex has been shown ${ }^{3}$ to be 1,920 million years old, and a corresponding expansion of the time-scale involving the dyke system becomes possible. The consequences in stratigraphy of these determinations and greater detail of the determinations will be presented elsewhere.

I wish to thank Mr. C. B. van Niekerk of the South African National Physical Research Laboratory for collecting the samples and undertaking the arduous and lengthy separations necessary ; Dr. D. I. Gough for helpful discussions on the palæomagnetic measurements ; and Dr. H. L. Allsopp for assistance in the mass spectrometry. My thanks are also due to the Carnegie Institution of Washington and the Nuffield Board of Trustees, for financial support.

Bernard Price Institute of G. D. L. SChreiner

Geophysical Research,

University of the Witwatersrand, Johannesburg.

March 14.

${ }^{1}$ Gough, D. I., Mon. Not. Roy. Astro. Soc., 7, 1956 (1956)

${ }^{2}$ Cooke, H. B. S., South African J. Sci., 50, 123 (1953).

${ }^{3}$ Schreiner, G. D. L., Proc. Roy. Soc., A (in the press).

\section{Annual Rainfall Distribution in East Africa}

Ir has been a general practice over the past fow years to assume that the annual rainfall amounts recorded at stations in East Africa follow a normal distribution law $w^{1,2}$; but this assumption has not been based on a detailed analysis of all the long-period data. The reason for this may be that an analysis of the station with the longest record (Padua, Italy, 225 years) has shown the distribution to be not significantly different from normal and so it was thought that this should hold true for other stations.

An initial analysis of thirty stations in East Africa, typical of the geographical and climatic zones, has been completed. This is the first stage of a full investigation of the 240 stations available with more than thirty years records. So far, it seems that areas of rainfall not normally distributed tend to be located in the west of the territory and the drier areas, but two exceptions to this are Nairobi (Kenya) and Gulu (north-east Uganda). Assuming the distribution to be normal, half the stations received one annual fall greater than expected, while some recorded amounts that would have been forecast only once in $1,000-7,000$ years. In all, 21 of the 30 stations proved to be not significantly different from normal, one being doubtful and eight not normal. There were three stations, Mbarara (Uganda), Fort Portal (Uganda) and Dodoma (Tanganyika), with a distribution not significantly different from normal when the outstandingly high year was omitted, so that normal limits were applicable, except at high values. Of the five stations remaining, four fitted a log-normal distribution, leaving only Nairobi non-defined. In view of this discrepancy another station about one mile away from the Nairobi site was examined, but this followed an identical pattern.

Much difficulty has been experienced while testing the stations for normality as most of them have only some 40-50 years records, thus making full momentfitting inadvisable. The tests used are Cornu's criterion, skewness limits and kurtosis limits, but with such small numbers no test is really foolproof.

It has become clear from this preliminary analysis of East African stations that it is not sound to assume normality of distribution without first testing the data for the station. Even nearby sites cannot be used with certainty, for Nairobi and Kabete, only 8 miles apart, show normal and not-normal distribution respectively. This fact makes prognostication based on normality rather unreliable, but it is hoped that some pattern will evolve when the work is completed.

The final, full investigation of the 240 stations will contain, as well as normality tests, the trends of the 30 -year moving mean and the reliability of sampling certain periods of observations.

I am indebted to the director of the East African Meteorological Department for permission to publish this initial report.

\section{East African Meteorological Department, Nairobi. March 7.}

Glover, J., and Robinson, P., J. Agric. Sci., 43, 275 (1953). 2 Manning, H. L., Proc. Roy. Soc., B, 144, 460 (1956).

\section{Control of Surface Concentration in the Diffusion of Phosphorus in Silicon}

A PROBLEM in the production of transistor structures by diffusion is to control the surface concentration at a required level (about $5 \times 10^{18}$ atoms/ $\mathrm{cm}^{3}$ in a typical case). Diffusion of phosphorus by conventional methods produces concentrations between $10^{20}-10^{21}$ atoms $/ \mathrm{cm}^{3}$ due to the high solubility of the phosphorus at the diffusion temperatures ${ }^{1}$. A method of obtaining desired values of surface concentration over the range $5 \times 10^{18}$ to $5 \times 10^{18}$ atoms $/ \mathrm{cm}^{3}$ by controlling the phosphorus vapour pressure has been successfully evolved.

Diffusion is carried out in a closed evacuated tube, one end of which, containing the silicon slices, is held in a diffusion furnace, the other, containing pure distilled yellow phosphorus, being maintained at temperatures in the range $-30^{\circ} \mathrm{C}$. to $+35^{\circ} \mathrm{C}$. controlled to $\pm 0 \cdot 5^{\circ} \mathrm{C}$. The silicon slices, doped with boron to $1 \mathrm{ohm} . \mathrm{cm}$. resistivity (a value chosen for transistor application), are lapped on 'Unirundum 85' powder, and then etched to a mirror finish with a mixture of nitric acid/hydrofluoric acid (80/20 per cent).

The hot part of the system, including the silicon slices, is thoroughly outgassed by baking up to $700^{\circ} \mathrm{C}$. before sealing off. After diffusion the surface concentration is determined by four probe-conduct. 